\title{
O USO PEDAGÓGICO DAS TECNOLOGIAS \\ DA INFORMAÇÃO E DA COMUNICAÇÃO NA FORMAÇÃO DOS FUTUROS DOCENTES NO QUEBEC
}

\author{
THIERRY KARSENTI ${ }^{* *}$ \\ STÉPHANE VILLENEUVE ${ }^{* * *}$ \\ CAROLE RabY***
}

\begin{abstract}
RESUMO: Será que os docentes que estão sendo formados no Quebec estão prontos para integrar as tecnologias da informação e da comunicação (TIC) num contexto escolar? Para responder a essa pergunta, uma pesquisa foi realizada junto a 2.065 futuros professores, 410 professores associados e 90 supervisores de estágio, oriundos das nove universidades francófonas que oferecem um programa de formação inicial de professores no Quebec (Canadá). Os resultados mostram que os futuros professores têm acesso aos equipamentos necessários para se familiarizar com as TIC e dominam bem as ferramentas tecnológicas básicas. Nossos dados também revelam que as usam, regular e criticamente, para planejar, comunicar, buscar informações, preparar materiais pedagógicos, resolver problemas ou se aprimorar no plano profissional. Apesar desse retrato muito promissor, nossos resultados também indicam que uma proporção muito pequena de futuros professores usa essas tecnologias em sala de aula. Nossa conclusão apresenta algumas recomendações.

Palavras-chave: Tecnologias da informação e da comunicação (TIC). Docentes. Competências. Formação. Computador. Tecnologias. Formação inicial. Aprimoramento professional.
\end{abstract}

* Tradução de Alain François, com revisão técnica de Cecília Borges.

** Professor titular da Faculdade de Ciências da Educação da Universidade de Montreal. E-mail: thierry.karsenti@umontreal.ca

*** Doutorando do Departamento de Psicopedagogia e Andragogia da Universidade de Montreal. E-mail: s.villeneuve@umontreal.ca

**** Professora do Departamento de Educação e Pedagogia da Universidade do Quebec, em Montreal. E-mail: raby.carole@uqam.ca

Educ. Soc., Campinas, vol. 29, n. 104 - Especial, p. 865-889, out. 2008

Disponível em <http://www.cedes.unicamp.br> 
O uso pedagógico das tecnologias da informação e da comunicação...

THE USE OF INFORMATION AND COMMUNICATION TECHNOLOGIES IN THE TRAINING OF QUEBEC'S FUTURE TEACHERS

ABSTRACT: Are the future teachers trained in Quebec ready to integrate the information and communication technologies (ICT) in an educational context? To answer this question, a survey was conducted among 2.065 future teachers, 410 associated teachers and 90 stage supervisors from the nine francophone universities that provide pre-service training for teachers, in Québec. Our results reveal that these future teachers have access to adequate equipment so as to familiarize themselves with ICT and master very well basic technological tools. The data collected also show they use them regularly and critically to plan, communicate, look for information, prepare pedagogic materials, solve problems or improve their professional skills. Despite this quite promising picture, our results also show that only few would-be teachers use these technologies in the classroom. Our conclusion brings forth a few recommendations.

Key words: Information and communication technologies (ICT). Teachers. Skills. Training. Computer. Technologies. Preservice training. Professional improvement.

\section{Introdução}

$\mathcal{E}$ m 1995, havia um pouco mais de 16 milhões de internautas na Terra. Hoje em dia, esse número ultrapassa os 750 milhões. Na maioria dos países industrializados, pelo menos $50 \%$ dos domicílios possuem um computador conectado à internet. Até os chamados países em desenvolvimento são arrastados por esse redemoinho tecnológico. $\mathrm{O}$ aumento exponencial da presença das tecnologias da informação e da comunicação (TIC) em nossa sociedade anuncia uma revolução antecipada, há muito, na educação? Prometida nos anos de 1970, louvada nos anos de 1980 e vista com um misto de respeito, temor e incredulidade nos anos de 1990, a sociedade mundial do saber teria se tornado, no século XXI, uma realidade incontornável na formação de professores? Essas tecnologias devem mesmo fazer parte dos programas de estudo? No Quebec, no resto do Canadá e em todos os cantos da América ou da Europa, elas já são parte integrante de vários programas de estudo para escolas primárias ou secundárias. Também são uma prioridade para a pedagogia universitária no conjunto dos estabelecimentos 
de estudos superiores dos países industrializados. Deseja-se, graças às TIC, fazer com que as pessoas aprendam melhor, mais, e até mesmo mais rápido... e a um custo menor.

Contudo, na educação, os desafios ainda são muitos. De fato, como observaram Bauer e Kenton (2005), mesmo se vários estudos da última década mostraram que as TIC são um meio eficiente de favorecer o êxito educacional dos estudantes, os professores ainda não as usam regularmente em sala de aula nem as integram ao seu currículo. Será que os resultados de pesquisas que mostram que os professores as usam pouco tendem a mudar? Será que os futuros professores que estão sendo formados no Quebec em 2007 estão verdadeiramente prontos para integrar as tecnologias da informação e da comunicação em sala de aula? Para responder a essas perguntas, apresentaremos os resultados de uma importante pesquisa, cujo objetivo era o de apresentar um retrato do nível de domínio das competências profissionais para integrar as tecnologias da informação e da comunicação (TIC) de 2.065 futuros professores oriundos de nove universidades francófonas do Quebec (Canadá).

\section{Contexto}

Por que se preocupar com a preparação dos futuros professores para os usos pedagógicos das TIC em contexto escolar? Porque a literatura científica dos últimos anos indica claramente que elas favorecem, em vários aspectos, o êxito educacional dos estudantes. Entretanto, embora essa mesma literatura científica revele também que os professores as usam raramente em contexto escolar, é preciso fazer prova de bom senso. Em 2007, o debate sobre a integração das TIC em contexto escolar não deve mais ser o da necessidade (ou não) de usá-las na escola. $\mathrm{O}$ debate deve antes focalizar como integrá-las à pedagogia. Neste texto, a primeira seção examina o seu impacto no êxito educacional dos alunos antes de analisar a questão da sua difícil penetração nas práticas pedagógicas em sala de aula. Em seguida, o contexto das TIC na formação dos futuros professores do Quebec é brevemente exposto para que o leitor menos familiarizado com a estrutura de formação dos professores no Quebec possa entender melhor tanto o contexto da pesquisa, quanto os resultados apresentados. 
O uso pedagógico das tecnologias da informação e da comunicação...

\section{O impacto das TIC no êxito educacional dos estudantes}

Nesses últimos anos, vários estudos ressaltaram o potencial das TIC para melhorar o ensino e favorecer o aprendizado. A literatura científica oferece muitas sínteses e meta-análises, como os trabalhos Schacter (1999), o número temático da revista Journal of Assisted Computer Learning, dirigido por Cox (2002), e, muito recentemente, a meta-análise de Balanskat, Blamire e Kefala (2006). Esses estudos apresentam seus impactos no êxito educacional dos estudantes de modos quantitativo e qualitativo.

No plano quantitativo, por exemplo, os trabalhos de Machin et al. (2006) revelam que as TIC têm um impacto significativo na qualidade da língua maternal. As pesquisas mostram que elas também permitem melhorar tanto as competências escritas, em geral, quanto a qualidade de apresentação das produções dos alunos e a quantidade de esforços despendidos por estes para melhorarem seus textos (ver Lewin et al., 2000; Passey, 2000). A OCDE (2004) e as pesquisas realizadas pela BECTA (British Educational Communications and Technology Agency [Agência de Tecnologias e Comunicações Educacionais Britânica] - 2006), Kessel et al. (2005), assim como as de Underwood (2005, 2006), indicam que as TIC têm um impacto positivo nos resultados dos estudantes em vários testes padronizados, em particular em matemática (OCDE, 2004). O seu impacto em matemática é especialmente evidente quando se trata de resolver problemas, exercer competências de cálculo e explorar relações (Clements, 2000; Yelland, 2003).

$\mathrm{Na}$ literatura científica, impactos ditos mais qualitativos dessas tecnologias no êxito educacional dos alunos costumam ser relatados em trabalhos de pesquisa. Os estudos do Institut technologique universitaire (ITU, 2004), da Ramboll Management (2005, 2006) e d'European Schoolnet (Redescolar Européia, 2004) revelam, por exemplo, que professores e pais estão convictos de que elas têm um impacto positivo no êxito educacional dos alunos. Uma corrente de pesquisas também revela o seu impacto nos alunos com dificuldades de aprendizado (SivinKachala \& Bialo, 2000). Finalmente, o que mais encontramos na literatura científica é que elas motivam os estudantes, tornam o aprendizado mais instigante e permitem, em particular, mas não exclusivamente, que os alunos com dificuldades invistam mais esforços na tarefa de aprendizado (Christmann \& Badgett, 2003; Evans, 2000; Sivin-Kachala \& 
Bialo, 2000), sejam mais atentos durante a realização da tarefa de aprendizado e não tenham medo de cometer erros (BECTA, 2006).

\section{A difícil penetração das TIC nas práticas pedagógicas}

Apesar dos impactos evidentes no êxito educacional dos alunos, o uso pedagógico das TIC em contexto escolar nunca deixou de representar um imenso desafio. De fato, a literatura científica continua mostrando que são pouco usadas em sala de aula (ver Balanskat et al., 2006; Bauer \& Kenton, 2005; BECTA, 2006; Cox, 2003; European Schoolnet, 2004; Kessel et al., 2005; McCrory Wallace, 2004; OCDE, 2004; Ramboll Management, 2006; Zhao \& Franck, 2003). Essa constatação repete-se em estudos realizados tanto na América do Norte quanto na Europa. Além disso, as conclusões de um estudo da OCDE (2004), Completing the foundation for lifelong learning: an OECD survey... (Completar as fundações para um estudo ao longo da vida: uma pesquisa da OCDE...) revelam como o arranjo dos horários de ensino, a organização das aulas e a fraca competência tecnopedagógica dos professores impedem que sejam verdadeiramente integradas na pedagogia. Esse relatório começa por ressaltar o uso decepcionante das TIC nas escolas desses países, embora os importantes investimentos desses 20 últimos anos permitiram que entrassem nesses estabelecimentos. As conclusões do relatório da OCDE também refletem essa decepção: "O uso da informática para fins pedagógicos no conjunto das escolas secundárias desses países é esporádico" (p. 133). Além do mais, observa-se que "apenas uma minoria de docentes nesse conjunto de países usa regularmente aplicativos informáticos correntes" (p. 133-134). Num artigo publicado no American Educational Research Journal, McCrory Wallace (2004) também nota que "Entretanto, os professores não estão bem preparados para ensinar com a internet, e a abrangência e a substância do seu uso são limitadas" (p. 447). Zhao e Franck (2003) também ressaltam que sua introdução na educação não logrou o sucesso esperado. O que a literatura científica e os últimos estudos da OCDE e de Bauer \& Kenton (2005) demonstram é que elas ainda não estão presentes em sala de aula, o que é um problema importante numa sociedade confrontada com o redemoinho das TIC (Balanskat et al., 2006). 
O uso pedagógico das tecnologias da informação e da comunicação...

As TIC e a formação dos futuros professores no Quebec

Para entender melhor o contexto no qual este estudo foi realizado, convém apresentar sumariamente o lugar ocupado por essas tecnologias na formação de professores no Quebec. Em 2001, o Ministério da Educação (MEQ) ${ }^{1}$ lançou La formation à l'enseignement: les orientations; les compétences professionnelles (A formação para o ensino: as orientações; as competências profissionais), documento que constitui a referência oficial em matéria de formação dos professores nas universidades do Quebec. ${ }^{2}$ No âmago desse texto, que objetiva orientar a formação de professores, estão 12 competências profissionais esperadas dos futuros professores no fim de sua formação inicial de quatro anos. Firmemente ancorado numa ótica de profissionalização e de abordagem cultural do ensino, esse referencial de competências visa, ultimamente, melhorar a qualidade da formação e, assim, as taxas de sucesso dos alunos, a qual anda problemática no Quebec (mais de 30\% não completam o secundário).

Entre as 12 competências profissionais identificadas pelo Governo, uma focaliza mais especificamente o uso pedagógico das TIC pelos professores: Integrar as tecnologias da informação e da comunicação para o preparo e a "pilotagem" de atividades de ensino-aprendizado, gestão do ensino e desenvolvimento profissional. Esta, por sua vez, desdobra-se em seis componentes:

1. Demonstrar um espírito crítico e nuançado em relação às vantagens e aos limites verdadeiros das TIC;

2. avaliar o potencial didático das TIC para o desenvolvimento de competências;

3. comunicar-se com a ajuda de ferramentas multimídias;

4. usar as TIC para buscar, interpretar e comunicar informaçôes e resolver problemas;

5. usar as TIC para constituir redes de trocas e de formação continuada;

6. ajudar os alunos a se apropriarem das TIC, a usá-las para seus aprendizados, a avaliar seu uso e a julgar criticamente as informações recolhidas. 
A competência para integrar as TIC, tal como formulada no referencial de competências profissionais para os futuros professores do Quebec, indica claramente que estes devem apropriar-se delas tanto para o planejamento quanto para a "pilotagem" ou a gestão do ensino. O docente recém-formado deve saber comunicar-se com a sua ajuda, ensinar com elas em sala de aula e planejar suas aulas com elas. Além do mais, deve ser capaz de estimular seus alunos a usarem as TIC para aprender melhor. Tudo isso sem perder de vista a missão da escola quebequense de educar, instruir e socializar. Também está indicado que elas devem participar do desenvolvimento profissional dos professores: na sua formação continuada, os professores devem recorrer a elas como ferramenta de aprendizado. A formulação da competência para integrálas no referencial de competência profissional dos professores mostra progressos importantes em relação à evolução das políticas em matéria de TIC e educação no Quebec. Desde a introdução da informática nas escolas, no final dos anos de 1960, o sistema educativo quebequense passou do ensino da informática per se (que almejava essencialmente iniciar os estudantes [alunos ou futuros professores] no uso do computador, da internet ou de várias ferramentas informáticas) para a integração pedagógica das TIC no ensino, de modo transversal.

\section{Metodologia}

\section{Participantes}

Financiado pelo Ministère de l'Éducation, du Loisir et du Sport du Québec (MELS - Ministério da Educação, do Laser e do Desporte do Québec), esse estudo foi conduzido nos nove estabelecimentos universitários francófonos daquele país que oferecem programas de formação inicial de professores. Os últimos resultados datam de 2006. $2.065 \mathrm{fu}$ turos professores inscritos nos terceiro e quarto ano de formação universitária participaram do estudo. Estes foram preferidos por terem uma experiência de sala de aula mais importante em razão dos estágios de formação prática. De fato, os alunos de terceiro ano que participaram da pesquisa já haviam realizado em torno de 60 dias de estágios em contexto escolar, e os do quarto ano, até 120 dias. Além do mais, a sua experiência com as TIC também era mais significativa. Além desses

Educ. Soc., Campinas, vol. 29, n. 104 - Especial, p. 865-889, out. 2008

Disponível em <http://www.cedes.unicamp.br> 
O uso pedagógico das tecnologias da informação e da comunicação...

2.065 futuros professores, 90 supervisores de estágio e 410 professores associados ${ }^{3}$ participaram do estudo para conhecermos sua opinião sobre o domínio da competência profissional em TIC por parte dos futuros professores, cujos estágios supervisionavam ou orientavam. Os resultados apresentados neste texto, entretanto, apenas dizem respeito aos 2.065 futuros professores.

\section{Instrumentos de medição}

Para conseguir alcançar o objetivo do estudo, isto é, apresentar um retrato do nível de domínio da competência profissional dos futuros professores para integrar as TIC, privilegiamos tanto a pesquisa por questionário como as entrevistas em grupo. Os questionários para os futuros professores eram divididos em três seçóes: a primeira focalizava informaçōes gerais, a segunda, as competências gerais para usar as TIC, e a terceira, o uso destas no ensino (nos estágios). O questionário incluía perguntas com avaliação em escala de Likert, perguntas fechadas e perguntas com respostas curtas. Cinco entrevistas em grupo, das quais participaram 34 futuros professores, permitiram completar a coleta dos dados.

\section{Métodos de análise dos dados}

As análises estatísticas foram realizadas com a ajuda do software SPSS 14.0, para tratar os dados oriundos das respostas com avaliação na escala de Likert e das perguntas fechadas. Por sua vez, os dados de natureza qualitativa, provenientes tanto das entrevistas em grupo quanto das perguntas com respostas curtas dos questionários, foram analisados com a ajuda dos software N'Vivo e FileMaker Pro, respectivamente, segundo o procedimento de análise de conteúdo preconizado por Van der Maren (1995):

1. Transcrição das respostas curtas (questionários) ou das gravações (grupos de discussão);

2. leituras e releituras das respostas curtas ou das transcrições para determinar os trechos significativos;

3. elaboração de grades de codificação com emergência de novos códigos; 
4. codificação dos segmentos;

5. codificação inversa para certificar-se de que os segmentos estavam no código certo;

6. comparação e condensação dos códigos (sobrecódigos);

7. elaboração de tabelas ou matrizes.

\section{Resultados}

Para alguns resultados, os dados dos futuros professores inscritos num programa de formação para ensinar no primário ${ }^{4}$ e no secundário $^{5}$ são apresentados separadamente. Essa precisão visa ressaltar certas diferenças interessantes. No Quebec, esses dois programas têm uma estrutura comum de quatro anos de formação universitária, que inclui vários cursos comuns, mas com especificidades inerentes ao contexto de ensino. Por exemplo, os futuros professores que se destinam ao ensino secundário têm uma concentração maior de cursos disciplinares (em francês, em matemática, em ciências etc.), ao passo que os que se destinam ao ensino primário devem seguir cursos que focalizam uma variedade de disciplinas (ciências humanas, francês, ciências da natureza etc.).

Os primeiros resultados apresentados dizem respeito ao acesso às tecnologias pelos futuros docentes. Logo a seguir, apresentamos o retrato de suas competências tecnológicas. Finalmente, como é importante relacionar os resultados do estudo desenvolvido com o objetivo de pesquisa, mas também para estabelecer um retrato mais preciso da competência profissional dos futuros professores para integrar as TIC, os resultados são apresentados em função dos seis componentes do referencial de competências do Ministério da Educação do Quebec (A formação para o ensino: as orientaçôes; as competências profissionais), mencionados anteriormente.

Futuros professores mais conectados que a população quebequense ou canadense em geral

Os resultados do estudo revelam que $98,8 \%$ dos futuros docentes inscritos no programa para o ensino primário (PEP) e 97,8\% dos inscritos no programa para o ensino secundário (PES) têm acesso a um 
O uso pedagógico das tecnologias da informação e da comunicação...

computador em seu domicílio e, aproximadamente, $92,1 \%$ (93,3\% no PEP e 91,4\% no PES) estão conectados à internet. Esse resultado mostra que os futuros professores são globalmente melhor conectados do que a população geral do Quebec (68\%) ou do Canadá (66\%) e os diplomados universitários quebequenses em seu conjunto (87\%) e ligeiramente melhor conectados do que os jovens adultos de 18 a 24 anos (97\%) (CEFRIO, 2007).

Fortes competências em software básicos; competências a desenvolver no uso de software mais específicos

Os dados recolhidos nesta pesquisa indicam que os futuros professores dominam os software básicos, os quais usam regularmente na sua formação universitária ou na sua vida cotidiana. De fato, numa escala de Likert com seis níveis ("nenhum", "principiante", "médio", "bom”, "muito bom" e "excelente"), mais de $95 \%$ dos futuros professores consideram seu conhecimento do uso de processadores de texto, correio eletrônico e "motores" de pesquisa (Google, Yahoo etc., e bases de dados como Eric, Francis, Quest etc.) e de navegação na internet entre "bom" e "excelente". Mais de $70 \%$ pensam que seu domínio dos software de apresentação é "bom", "muito bom" ou "excelente", enquanto aproximadamente $68 \%$ qualificam sua competência do mesmo modo, no que diz respeito ao uso de várias ferramentas de comunicação (fórum e chat). Entretanto, o estudo também revela que os professores em formação estão muito menos à vontade com outras ferramentas tecnológicas, cujo uso pedagógico pode ser importante na educação. Por exemplo, aproximadamente 52\% qualificam sua competência para usar uma câmera numérica como superior à "média" e apenas $43 \%$ possuem um domínio superior à "média" no uso de planilhas eletrônicas (de tipo Excel), as quais, contudo, são úteis tanto na gestão do ensino como no ensino de dadas disciplinas como matemática, ciências etc. Os futuros docentes são menos familiarizados ainda com o uso de software de edição de imagens, de vídeo ou de criação de páginas web (respectivamente, 29\%, 23\% e 14\% dos futuros professores qualificam sua competência como superior à "média").

\section{Componentes da competência profissional para integrar as TIC}

Como dissemos anteriormente, esta seção apresenta os resultados em função dos seis componentes da competência do referencial do 
Ministério da Educação do Quebec. Os dados provêm tanto dos questionários quanto das entrevistas em grupo.

\section{Bom espirito crítico em relação às TIC na sociedade}

As entrevistas em grupo mostram que os futuros docentes em formação parecem ter desenvolvido um bom espírito crítico em relação às TIC. Por um lado, percebem muitas vantagens na sua integração em sala de aula, principalmente no seu ensino (acesso a recursos; gestão de aula, preparação de material didático, gestão do material didático e comunicação facilitadas; variação do ensino). Também mencionam algumas vantagens no plano do aprendizado dos alunos (maior motivação, possibilidade de desenvolver competências, melhoria da relação docente-aluno etc.). Por outro lado, embora percebam muitas vantagens na integração pedagógica das TIC, os futuros professores também são críticos quanto aos seus benefícios no contexto escolar. Assim, notam vários desafios e até mesmo problemas inerentes ao seu uso no ensino (insuficiência, obsolescência e instabilidade dos equipamentos, complexidade técnica, aspecto "cronófago" das TIC, maior dificuldade na gestão da sala de aula) e no aprendizado (diferença entre os alunos que têm ou não um computador em casa, atenção maior à forma do que ao conteúdo, diminuição da qualidade da língua escrita). Além do mais, os futuros professores são conscientes dos limites de certas informaçōes encontradas na internet, mas conseguiram desenvolver várias estratégias para certificar-se da confiabilidade dessas informações (estratégia de triangulação, confiabilidade do site etc.). Alguns também enfatizaram, nas entrevistas em grupo, a possível dependência de certos adolescentes para com o computador. Esses resultados são positivos e revelam que os futuros professores formados no Quebec desenvolvem, em geral, um bom espírito crítico a respeito dos usos das TIC na educação. Para eles, estas não são nem uma panacéia, nem um novo mal para a educação.

2. Maior uso do e-mail; desinteresse pelas outras ferramentas de comunicação

Nossos resultados ressaltam que os futuros docentes se comunicam regularmente via e-mail. De fato, $65 \%$ e $74,3 \%$ dos futuros

Educ. Soc., Campinas, vol. 29, n. 104 - Especial, p. 865-889, out. 2008 
O uso pedagógico das tecnologias da informação e da comunicação...

professores inscritos no PEP e no PES, respectivamente, usam esse meio para se comunicarem com outros colegas de modo quase diário, e isso em vínculo com a sua formação. Esse resultado é interessante, pois mostra explicitamente que as TIC fazem doravante parte do cotidiano dos professores em formação. Contudo, vale salientar que o e-mail é muito menos usado para comunicar com os alunos, durante os estágios $(18,2 \%$ no PEP e $15,2 \%$ no PES), ou com os pais de alunos ( $4,7 \%$ no PEP e $3,9 \%$ no PES) e que outras ferramentas de comunicação como fóruns e sites de chat são muito menos usadas para suas necessidades profissionais (respectivamente, $30,2 \%$ e $22,9 \%$ no PEP e $39,2 \%$ e $27,1 \%$ no PES). Por que recorrem menos aos fóruns? Parece que os futuros docentes em formação têm de fazer malabarismos com uma infinidade de tarefas e que preferem, possivelmente, usar o e-mail por ser mais simples, e até mesmo mais natural, para eles.

3. Avaliar o potencial das TIC para desenvolver competências: uma consciência que precisa ser desenvolvida

Os resultados dos grupos de discussão demonstram que os futuros professores parecem pouco propensos a usar as TIC para favorecer o desenvolvimento de diversas competências nos seus alunos. Embora pareçam conscientes dos seus benefícios para facilitar o acesso dos estudantes a recursos e do entusiasmo que estas geram entre os alunos, poucos parecem sensíveis às suas vantagens potenciais para o desenvolvimento de competências nos alunos. Mesmo assim, nas entrevistas em grupo, raros respondentes enfatizaram o seu potencial para aumentar as competências dos alunos para explorar informações, resolver problemas, exercer seu juízo crítico, cooperar ou se comunicar. Alguns futuros professores também mencionaram que podiam ajudar a desenvolver as competências dos estudantes em línguas (escrever textos variados, revisar seus textos, aumentar seu vocabulário) e em matemática (resolver problemas, efetuar transformações, medir áreas e perímetros, encontrar uma reta por reflexão etc.). Outros também afirmaram ser possível desenvolver uma grande variedade de competências nos alunos com a ajuda das TIC. Em suma, parece que poucos futuros professores são capazes de avaliar o pleno potencial didático das ferramentas informáticas e das redes para que seus alunos aprendam melhor ou aumentem suas competências. Esse componente da competência 
profissional para integrar as TIC não parece, portanto, completamente dominado pelos futuros professores; falta desenvolvê-lo.

\section{Um forte uso das TIC para buscar informaçōes e resolver problemas}

Alguns resultados do estudo são muito animadores para a formação e a profissão docentes no Quebec, em particular no que diz respeito à capacidade dos futuros professores para usar eficientemente as TIC para buscar, interpretar, comunicar informações e para resolver problemas. De fato, $99,7 \%$ dos futuros docentes do PEP e 99,3\% do PES usam "motores" de pesquisa na internet para buscar informações (ver figura 1). Este resultado mostra que, para os futuros professores, a internet se tornou a primeira fonte de acesso à informação.

\section{Figura 1}

Percentagens de uso, pelos futuros professores primários e secundários, de "motores" de pesquisa para encontrar informaçôes

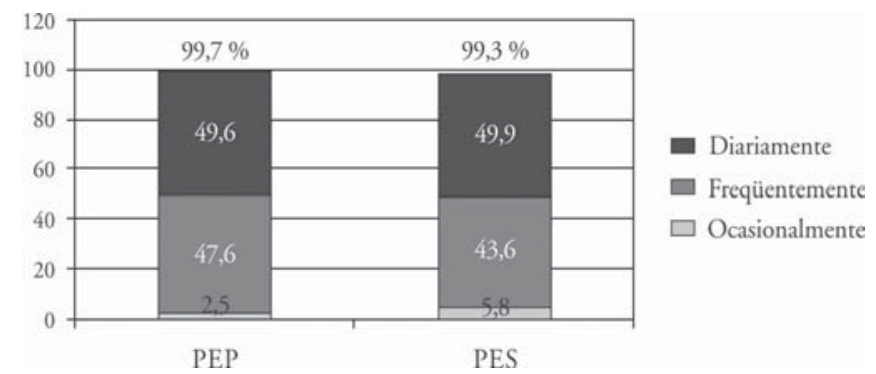

Este resultado, confirmado pelas entrevistas em grupo, também revela que uma das principais vantagens das TIC para o futuro docente e, possivelmente, para qualquer estudante universitário é o acesso fácil, diversificado, descentralizado, livre e, geralmente, grátis à informação. Além de permitirem acessar recursos até então dificilmente acessíveis, as TIC também facilitam uma mutualização dos conhecimentos. Antigamente ancorada numa lógica de difusão do saber, a formação dos professores deve agora enfrentar a lógica da navegação do saber. De fato, com um número crescente de futuros professores mergulhados na 
O uso pedagógico das tecnologias da informação e da comunicação...

cultura cada vez mais universal da internet, muitas pessoas esperam encontrar na universidade e nos programas de formação dos professores a comodidade, a rapidez e a facilidade de acesso à informação possibilitada pela web. Longe de permanecerem passivos, esperando que o saber lhes seja entregue, os futuros professores parecem antes muito hábeis em navegar para encontrar as informaçōes que buscam ou entrar em contato com seus colegas (por intermédio das TIC) para obter ajuda, adquirir conhecimentos ou desenvolver competências.

\section{As TIC para o desenvolvimento profissional?}

O quinto componente do referencial para os futuros professores diz respeito ao seu uso para o desenvolvimento profissional. Mais precisamente, o futuro docente deveria ser capaz de usá-las eficientemente para constituir redes de trocas e de formação continuada no seu próprio campo de ensino e na sua prática pedagógica. Os resultados do estudo revelam que $72,0 \%$ e $72,9 \%$ dos futuros docentes do PEP e do PES, respectivamente, afirmam usá-las (mais especificamente recursos disponíveis na internet, sites pedagógicos ou oficiais e trocas via meios eletrônicos de comunicação) para se aprimorarem. Nosso estudo demonstra que os futuros professores usam as tecnologias e, mais particularmente, as ferramentas de comunicação para se desenvolverem no plano profissional. Essa competência é importante para eles. De fato, como indicado num estudo precedente, há mais de quinze anos que o governo do Québec anseia pela presença de uma cultura de colaboração, ou até mesmo de um profissionalismo coletivo, entre os professores (Conseil supérieur de l'éducation [Conselho superior da educação], 1991), para responsabilizá-los pelo êxito educacional dos alunos. Essa aspiração do Estado também concerne aos futuros professores, que serão chamados a ocupar um lugar importante no corpo docente nos próximos anos. Nossos resultados mostram que, embora essa colaboração se limite, às vezes, ao compartilhamento de experiências vivenciadas nos estágios ou a pedidos de ajuda, ela permanece importante para os futuros professores, pois poderia permitir que desenvolvessem competências que não conseguiram dominar na sua formação inicial. Vários estudos mostram que a cultura de colaboração garante o desenvolvimento profissional dos professores, assim como o êxito da implantação de qualquer reforma escolar (Kluth \& Straut, 2003). Enquanto, há vários 
anos, o Quebec custa a implementar sua reforma do ensino secundário, as TIC talvez possam servir de catalisador para uma maior colaboração entre os futuros professores prestes a ocupar um cargo, favorecendo assim o êxito educacional de um maior número de alunos.

\section{Estimular os alunos a usar as TIC na escola}

O sexto componente da competência profissional para integrar as TIC diz respeito ao seu uso em sala de aula pelos futuros professores e até mesmo à incitação dos alunos a usá-las para aprender. Os resultados da pesquisa indicam que os futuros professores as usam essencialmente para planejar o seu ensino. De fato, aproximadamente $78 \%$ destes $(79,5 \%$ no PEP e $77,3 \%$ no PES) se valem delas regularmente para planejar suas aulas, diária ou semanalmente (ver figuras 2 e 3). Durante uma entrevista de grupo, um participante observou: "Faço todos os meus planejamentos no computador. Assim, podem ser modificados rapidamente". Outros dados recolhidos nas entrevistas em grupo mostram que os professores em formação usam as TIC para preparar seu material didático e pedagógico, ao passo que alguns recorrem à internet para buscar imagens ou textos pertinentes, encontrar idéias para conceituar atividades pedagógicas, "encontrar liçôes já preparadas" etc.

\section{Figura 2}

Percentagens de uso das TIC para planejar e preparar atividades de ensinoaprendizado entre os futuros professores primários
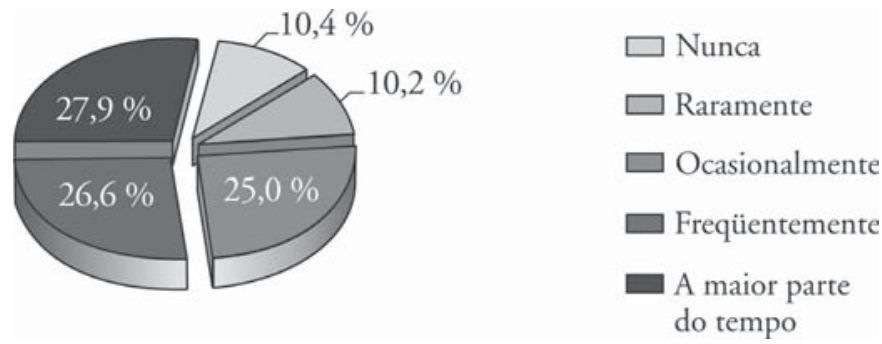

Educ. Soc., Campinas, vol. 29, n. 104 - Especial, p. 865-889, out. 2008

Disponível em <http://www.cedes.unicamp.br> 
O uso pedagógico das tecnologias da informação e da comunicação...

Figura 3

Percentagens de uso das TIC para planejar e preparar atividades de ensino-aprendizado

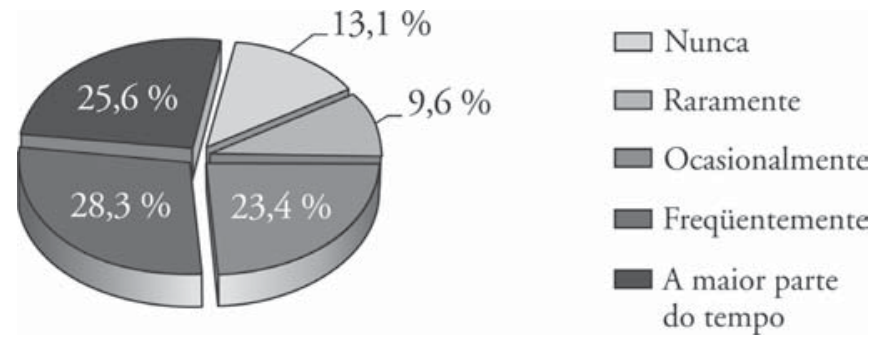

O ponto menos animador do estudo, o qual, contudo, confirma a grande maioria dos resultados de pesquisas internacionais realizadas neste campo (ver, por exemplo, a pesquisa da OCDE, de 2004), mostra que os futuros docentes, embora inscritos em uma formação para o ensino primário ou secundário, ainda usam muito pouco essas tecnologias em sala de aula. De fato, apenas 15,6\% dos futuros professores primários afirmam recorrer muito regularmente as TIC em sala de aula (figura 4). Este resultado é mais decepcionante ainda quando sabemos que todas as escolas primárias do Quebec estão conectadas à internet desde 1999 e que todas possuem computadores há muitos anos. Além do mais, em muitas dessas escolas, a informática é matéria obrigatória para os alunos segundo o horário previsto pela grade curricular, há vários anos. No secundário, os resultados do estudo realizado junto aos $2.065 \mathrm{fu}$ turos professores, provenientes dos quatro cantos do Quebec, são ainda mais preocupantes. Apenas 6,8\% dos futuros professores declaram usar as tecnologias muito regularmente em sala de aula (figura 5).

Este resultado confirma a constatação feita pela OCDE três anos atrás. Apesar dos investimentos, nesses 20 últimos anos, nas escolas do Quebec, o uso da informática em sala de aula continua decepcionante. A grande maioridade dos futuros professores que realizaram entre $60 \mathrm{e}$ 120 dias de estágio em escolas primárias ou secundárias recorre esporadicamente à informática para fins pedagógicos em sala de aula. De fato, apenas uma minoria dos futuros docentes de todas essas universidades que participaram da pesquisa lança mão das TIC regularmente. 
Contudo, os usos dessa minoria de futuros professores são bastante variados: pesquisas na internet, apresentações (com a ajuda de um software de tipo PowerPoint) de informações sobre um assunto particular, imagens ou vídeos, ensino de noções específicas ou, ainda, explicaçōes sobre como se servir de uma ferramenta que os estudantes, por sua vez, terão de usar.

\section{Figura 4}

Percentagens de uso das TIC em sala de aula entre os futuros professores primários

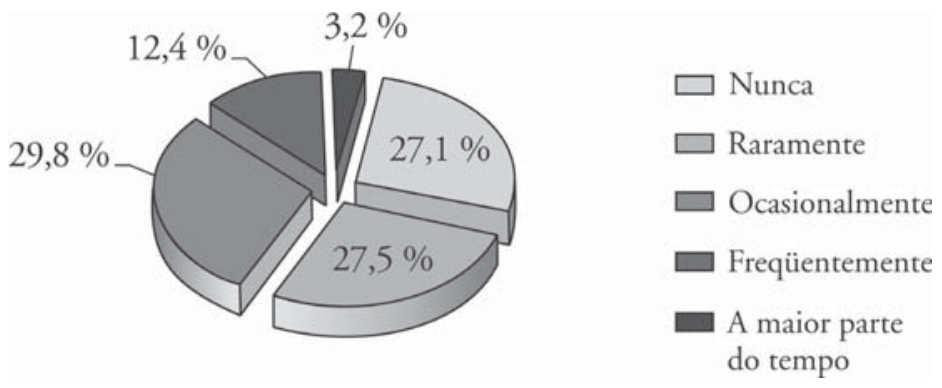

Figura 5

Percentagens de uso das TIC em sala de aula entre os futuros professores secundários

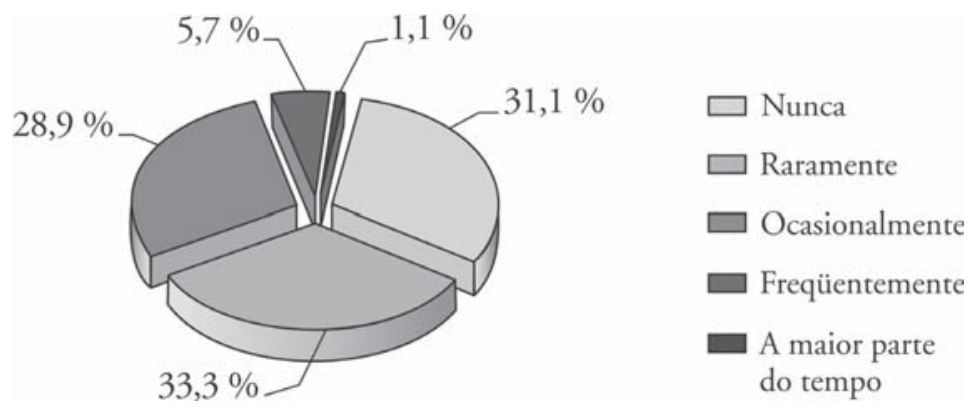

Educ. Soc., Campinas, vol. 29, n. 104 - Especial, p. 865-889, out. 2008

Disponível em <http://www.cedes.unicamp.br> 
O uso pedagógico das tecnologias da informação e da comunicação...

Quanto à capacidade dos futuros professores para incentivar seus alunos a usar as TIC em aula, os resultados obtidos nesta pesquisa mostram que os seus níveis de competência ainda são insuficientes (figura 6). De fato, $67,9 \%$ dos futuros professores primários estimulam os seus alunos a empregá-las em contexto escolar. No secundário, essa proporção cai para 53,4\%. Este resultado é particularmente perturbador se levarmos em conta o fato de que o uso das tecnologias está se tornando uma prática cada vez mais inserida no cotidiano da sociedade. Com efeito, uma pesquisa do CEFrio (2007) mostrou que mais de 97\% dos jovens do Quebec estão conectados à internet. É, portanto, importante que os docentes sejam capazes de favorecer o uso pedagógico das TIC em contexto escolar.

\section{Figura 6}

Proporção de docentes do primário (PEP) e do secundário (PES) que estimulam seus alunos a usar as TIC em contexto escolar

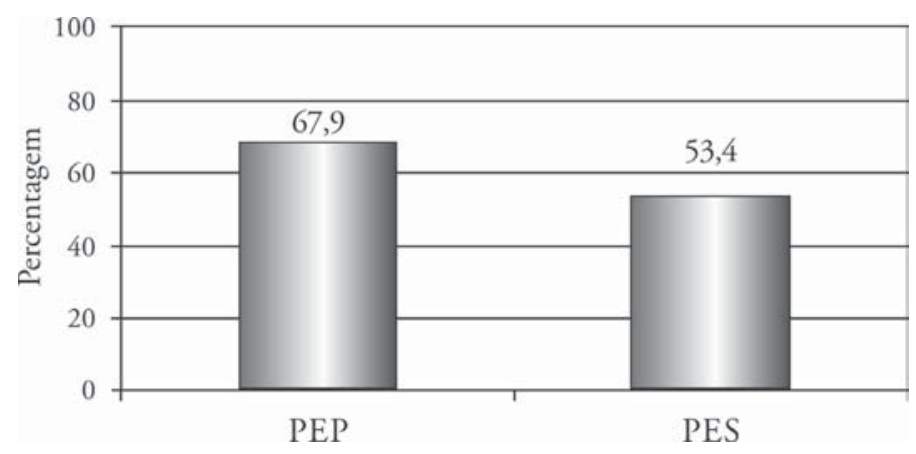

Algumas análises estatísticas inferenciais também foram realizadas para melhor compreender certos fatores suscetíveis de explicar essa falta de uso das TIC em sala de aula. Elas revelaram que quem seguiu um curso de integração das TIC na sua formação universitária $(M=2,79, E T=0,96)$ está significativamente mais propenso a estimular seus alunos a usá-las do que os outros $(M=2,45, E T=1,01)$, $t(2021)=5,88, p<0,001$. No que diz respeito à inclusão de atividades de aprendizado que recorram às TIC, os futuros professores que 
seguiram um curso de integração das TIC $(M=2,63, E T=0,93)$ estão significativamente mais dispostos a planejar atividades de aprendizado que recorram a elas do que os outros $(M=2,30, E T=0,93), t(2032)=$ $5,83, p<0,001$.

\section{Conclusão: condições para vencer, desafios a enfrentar}

A primeira constatação da pesquisa realizada no conjunto das universidades do Quebec que oferecem um programa de formação inicial de professores é animadora: o cotidiano dos futuros professores está cada vez mais marcado pelas TIC, uma vez que todos, ou quase, possuem um computador pessoal e têm acesso à internet em seu domicílio.

No geral, os resultados da pesquisa são animadores em vários aspectos. De fato, embora continuem confirmando vários estudos (entre outros, Bennett \& Daniel, 1999; Brinkerhoff et al., 2001; Swain, 2004, 2006) que ressaltaram as boas competências técnicas básicas dos futuros professores em contraste com a sua fraca capacidade para integrar as TIC em sala de aula, os resultados do presente estudo parecem mais promissores. Os futuros professores do Quebec têm à sua disposição tanto os equipamentos necessários para se familiarizarem com as TIC, quanto o domínio das ferramentas básicas. Os dados indicam também que eles as usam, regular e criticamente, para se comunicar, buscar informações, resolver problemas ou desenvolver-se no plano profissional. Embora seja verdade que esses fatores são essenciais, mas não suficientes, para a integração pedagógica das TIC, trata-se, contudo, de condições vencedoras que descortinam perspectivas interessantes para um futuro próximo.

Os resultados também revelaram que a maioria dos futuros professores usa as TIC para planejar e preparar suas atividades de ensinoaprendizado, mesmo se ainda são poucos os que estimulam seus alunos a usá-las no âmbito de atividades em sala de aula. A pesquisa mostra, portanto, que existe um uso importante das TIC pelos futuros professores, mas que este se situa essencialmente fora da sala de aula, em particular para se comunicar, planejar seu ensino e buscar informações. Os dados recolhidos indicam que a maioria dos futuros docentes ainda não conseguiu fazer passar esse uso externo para dentro da sala de aula.

No entanto, embora esse uso em sala de aula, per se, pelos futuros professores ainda represente um imenso desafio, nota-se que já existem 
O uso pedagógico das tecnologias da informação e da comunicação...

várias iniciativas interessantes, ainda que isoladas e até mesmo esporádicas. Talvez seja o caso de aproveitar essas iniciativas e difundi-las junto aos outros professores em formação. Como uma grande maioria deles usa as TIC para se comunicar e se desenvolver no plano profissional, videoclipes mostrando seus colegas usando-as pedagogicamente em sala de aula, por exemplo, poderiam ser espalhados rapidamente e, possivelmente, inspirar um maior número de futuros professores a lançar mão dessa via tecnopedagógica.

Nosso estudo também mostrou, de modo significativo, que os futuros professores que recebem uma melhor formação sobre o uso pedagógico das TIC têm cada vez mais chances de usá-las para planejar atividades de aprendizado que recorram a elas e de incitar seus alunos a usá-las em sala de aula. Com efeito, pede-se praticamente o impossível aos professores em formação que não seguiram tais cursos: integrar as TIC durante os estágios sem nunca ter realmente aprendido como fazer isso.

Por que alguns futuros docentes do Quebec não recebem muita formação para a integração pedagógica das TIC, se é obrigatório desenvolver essa competência? Embora essa questão seja delicada, ela merece ser tratada. No Quebec, entre 1993 e 2001, os futuros professores haviam de seguir, no decorrer de sua formação, um ou mais cursos de informática, nos quais aprendiam, por exemplo, a conhecer as partes do computador, assim como certas linguagens de programação. Ora, vários estudos mostraram que essas aulas não tiveram o menor impacto na integração pedagógica das TIC em sala de aula. Em 2001, apoiando-se no documento de orientação do Ministério da Educação ( $A$ formação para o ensino: as orientaçôes; as competências profissionais), alguns programas de formação de dadas universidades decidiram abolir esses cursos de informática e substituí-los por outros que focalizam a integração pedagógica das TIC. Outras preferiram optar por fazer da integração das TIC uma competência transversal, que seria abordada no conjunto dos cursos da formação inicial dos professores de seu programa ou de sua universidade. Embora, no plano teórico, essas iniciativas sejam muito interessantes, na prática as coisas correram de outro modo.

Mesmo se a supressão dos cursos sobre a integração pedagógica das TIC embasava-se na hipótese de que todos os formadores participariam do desenvolvimento dessa competência por seu próprio uso das TIC, os resultados da pesquisa indicam que não é, absolutamente, o 
caso. Ao sentirem a pressão desse novo encargo, muitos formadores universitários passaram a usar PowerPoint para ensinar. Viram nisso um modo acessível, para eles, de responder a essa nova demanda para que se faça da integração pedagógica das TIC uma competência transversal. Assim, por vários motivos, parece que o principal uso das TIC, ao qual os futuros professores estejam expostos, é a apresentação de slides (de tipo PowerPoint) com a ajuda de um computador. Entretanto, essa pedagogia expositiva que mal aproveita as TIC em nada serve de modelo aos futuros professores que desejam favorecer a integração pedagógica das TIC em sala de aula. Será que o fato de ensinar a didática do francês, por exemplo, por meio de PowerPoint, para apresentar noçôes aos futuros professores, os estimula realmente a desenvolverem essa competência? Será que o fato de usar PowerPoint para ensinar um curso sobre os fundamentos da educação desenvolve realmente a capacidade dos futuros professores para fazer um uso pedagógico das TIC? Os resultados deste estudo levantam sérias dúvidas a este respeito. Contudo, a responsabilidade por essa lacuna na formação dos professores do Quebec não recai necessariamente sobre os formadores universitários que não são especialistas em integração pedagógica das Tic. Deveríamos censurar psicólogos, lingüistas ou matemáticos por não terem se tornado, também, especialistas em integração pedagógica das TIC com a nova reforma da formação para o ensino? De modo algum, e isto, mesmo se considerarmos que algumas ações adaptadas ao nível destes poderiam ser implementadas.

Atualmente, nas universidades que suprimiram os cursos de TIC, o problema continua e uma coisa está certa: a ausência de formação para a integração pedagógica das TIC, per se, tem um impacto direto no seu uso pelos futuros professores em sala de aula. Sem o retorno ou a abertura de cursos reais sobre a integração pedagógica das TIC, parece que os futuros professores formados nesses programas e universidades são definitivamente penalizados. De fato, no momento, os futuros professores aprendem apenas como, entre outros, usar PowerPoint para apresentar noções em cursos geralmente magistrais. Ora, a integração pedagógica das TIC no contexto escolar exige antes um amplo leque de competências e não pode, de modo algum, limitar-se a isso (ver Karsenti \& Larose, 2005).

À luz do conjunto de resultados apresentados aqui, é importante que todos os atores da educação envolvidos na formação de professores 
O uso pedagógico das tecnologias da informação e da comunicação...

se concertem para apoiar os futuros professores na integração pedagógica das TIC e, portanto, no domínio da competência profissional para integrá-las. Além disso, como Karsenti e Gauthier (2006) mostraram recentemente, "O fato de a escola demorar cada vez mais para absorver as mudanças sociais não é surpreendente nem preocupante. (...) $\mathrm{O}$ importante talvez não seja tanto a questão do momento da chegada das TIC nas salas de aula, mas a de seu uso criterioso e pedagógico no ensino para o cumprimento das finalidades da escola" (p. 4). Daí a importância, segundo nós, de inscrever a integração pedagógica das TIC entre as prioridades da formação profissional dos professores e de encontrar modos de avaliar, regularmente, os progressos feitos pelos futuros professores em formação.

Recebido e aprovado em setembro de 2008.

\section{Notas}

1. Atualmente, Ministère de l'Éducation, du Loisir et du Sport (Mels - Ministério da Educação, do Laser e do Desporte).

2. No Quebec, a formação dos docentes ocorre em meio universitário e consiste em quatro anos de formação teórica e prática. Além das disciplinas obrigatórias e eletivas, os futuros docentes devem realizar, durante a sua formação, 120 dias de estágio em meio escolar (em torno de 700 horas dividas em quatro estágios, um a cada ano de formação).

3. No Quebec, os professores associados são os titulares de classe, que acolhem os estagiários em suas salas de aula, nas escolas primárias e secundárias.

4. O baccalauréat (equivalente à graduação em uma Licenciatura) em educação pré-escolar e ensino primário habilita para dar aulas a alunos entre 4 e 11 anos, aproximadamente.

5. O baccalauréat em ensino secundário habilita para dar aulas a alunos entre 12 e 17 anos, aproximadamente.

\section{Referências}

BALANSKAT, A.; BLAMIRE, R.; KEFALA, S. The ICT impact report. A review of studies of ICT impact on schools in Europe. European Communities: European Schoolnet, 2006.

BAUER, J.; KENTON, J. Toward technology integration in the schools: why it isn't happening. Journal of Technology and Teacher Education, v. 13, n. 4, p. 519-546, 2005. 
BECTA. The BECTA Review 2006: evidence on the progress of ICT in education. Coventry, UK: BECTA, 2006.

BENNETT, C.; DANIEL, L. Preparing novice teachers to use technology: do they practice what we teach?. In: Price, J. et al. (Ed.). Proceedings of Society for Information Technology and Teacher Education International Conference 1999. Chesapeake, VA: AACE, 1999. p. 11081111.

Brinkerhoff, J. et al. An assessment of technology skills and classroom technology integration experience in preservice and practicing teachers. In: CraWford, C. et al. (Ed.). Proceedings of Society for Information Technology and Teacher Education International Conference 2001. Chesapeake, VA: AACE, 2001. p. 1866-1871.

CEFRIO. Netendances 2006: évolution de l'utilisation d'internet au Québec depuis 1999. Montréal, 2007.

CHRISTMANN, E.; BADGETT, J. A meta-analytic comparison of the effects of computer-assisted instruction on elementary students' academic achievement. Information Technology in Childhood Education Annual, n. 1, p. 91-104, 2003.

CLEMENTS, D.H. From exercises and tasks to problems and projects - unique contributions of computers to innovative mathematics education. The Journal of Mathematical Behavior, v. 19, n. 1, p. 9-47, 2000 .

COX, F. The digital divide: opportunities for information literacy. Society for Information Technology and Teacher Education International Conference 2003, n. 1, p. 875-878, 2003.

COX, M.J. Information and communication technologies: their role and value for science education. In: Monk, M.; Osborne, J. (Ed.). Good practice in science teaching - what research has to say. London: Routledge, 2002. p. 142-158.

EUROPEAN SCHOOLNET. ERNIST ICT Schoolportraits. European Communities: European Schoolnet, 2004.

ITU. International Telecommunication Union. Geneva, 2004.

Educ. Soc., Campinas, vol. 29, n. 104 - Especial, p. 865-889, out. 2008 
O uso pedagógico das tecnologias da informação e da comunicação...

KARSENTI, T.; GAUTHIER, C. Les TIC bouleversent-elles réellement le travail des enseignants? Formation et profession, v. 12, n. 3, p. 2-4, 2006.

KESSEL, N. van et al. ICT education monitor: eight years of ICT in schools. Netherlands: Ministry of Education, Culture and Science, 2005.

KLUTH, P.; STRAUT, D. Do as we say and as we do: teaching and modeling collaborative practice in the university classroom. Journal of Teacher Education, v. 54, n. 3, p. 228-240, 2003.

LEWIN, C. et al. The KS1 literacy evaluation project using low cost computers. Coventry, UK: BECTA, 2000.

MACHIN, S. et al. New technologies in schools: is there a pay off? Germany: Institute for the Study of Labour, 2006.

McCRORY WALLACE, R. A framework for understanding teaching within the Internet. American Educational Research Journal, v. 41, n. 2, p. 447-488, 2004.

MINISTÈRE de L'éducation Du Quebec. La formation à l'enseignement: les orientations, les compétences professionnelles. Québec: Ministère de l'Éducation, 2001.

ORGANIZATION For Economic Co-Operation And Development (OCDE). Completing the foundation for lifelong learning: an OECD survey of upper secondary schools. Paris: OECD, 2004.

PASSEY, D. Developing teaching strategies for distance (out-ofschool) learning in primary and secondary schools. Educational Medial International, v. 37, n. 1, p. 45-57, 2000.

RAMBOLL Management. Evaluation of ITMF: overall results. Copenhagen: Ramboll Management, 2005.

RAMBOLL Management. E-learning Nordic 2006. Impact of ICT on education. Copenhagen: Ramboll Management, 2006.

SCHACTER, J. The impact of education technology on student achievement: what the most current research has to say. Santa Monica, CA: Milken Family Foundation, 1999. 
SIVIN-KACHALA, J.; BIALO, E.R. 2000 research report on the effectiveness of technology in schools. 7. ed. Washington, DC: Software $\&$ Information Industry Association, 2000.

SWAIN, C. They can talk the talk but will they walk the walk?. In: CraWford, C. et al. (Ed.). Proceedings of Society for Information Technology and Teacher Education International Conference 2004. Chesapeake, vA: AACE, 2004. p. 2688-2694.

SWAIN, C. Preservice teachers self-assessment using technology: determining what is worthwhile and looking for changes in daily teaching and learning practices. Journal of Technology and Teacher Education, v. 14, n. 1, p. 29-59, 2006.

UNDERWOOD, J. et al. Impact of broadband in schools. Nottingham, UK: BECTA, 2005.

UNDERWOOD, J. et al. ICT test bed evaluation-evaluation of the ICT test bed project. Nottingham, UK: Trent University, 2006.

VAN DER MAREN, J.-M. Méthodes de recherche pour l'éducation. 2. éd. Montréal: Les Presses de l'Université de Montréal, 1995.

YELLAND, N. Learning in school and out: formal and informal experiences with computer games in mathematical contexts. In: MARSHALL, G.; KATZ, Y. (Ed.). Learning in school, home and community: ICT for early and elementary education. London: Kluwer Academic, 2003.

ZHAO, Y.; FRANK, K.A. Factors affecting technology uses in schools: an ecological perspective. American Educational Research Journal, v. 40, n. 4, p. 807-840, 2003. 